\title{
Design of Products for Winter Wheat Agro-Meteorological Index Insurance in Jiangsu Province
}

\author{
Cao Jie, Li Sijia and Yang Li \\ Nanjing University of Information Science \& Technology, School of Economics \& \\ Management, Nanjing 210044, China \\ lisijia890919@126.com
}

\begin{abstract}
Agro-meteorological index insurance is an innovative agricultural insurance product that has solved problems of conventional agricultural insurances including excessive cost and moral hazard. Agro-meteorological index insurance has become an effective agricultural insurance scheme. This paper primarily uses meteorological data and winter wheat yield data in the Jiangsu Province for the last 35 years to build a yield loss model based on which we designed an agro-meteorological index. Using production data and the experience rate method, we calculate pure premium rates for winter wheat in different cities for different deductible amounts. According to the calculation results, we divided the Jiangsu Province into three regions with different deductible amounts and determined pure premium rates and pure premiums for each city, thereby completing the design of a winter wheat meteorological index insurance product. Our study designed specific insurance products for different areas; it has a good guiding significance for the agricultural insurance in Jiangsu province research.
\end{abstract}

Keywords: Winter wheat; agro-meteorological index insurance; pure premium rates; Jiangsu Province

\section{Introduction}

Agriculture is the most important element of human society. Agricultural production has been reduced because of frequent meteorological disasters, which are unpredictable, and therefore, not preventable. In the last 200 years, advances in science have yielded several useful methods to respond to meteorological disasters, however, we can never completely prevent these disasters. It is necessary to provide agricultural insurance to protect the safety of food supplies using economic theory. Traditional agricultural insurance products have several problems including excessive cost and moral hazard; therefore, the applications of the insurance are limited. In the last few years, the development of agro-meteorological index insurance has provided a new way to solve the problems [1-3]. This insurance is based on specified agriculture meteorological elements, and there is no need to separately evaluate individual sites because it is not dependent on real crop losses [4].

Some studies on agro-meteorological index insurance have been performed. Skees (1999) [5] provided a viable method for designing a meteorological insurance contract and has put drought agro-meteorological index insurance in practice; South Africa uses agrometeorological index insurance to address frost disasters in apple orchards; Canada and America use agro-meteorological index insurance for corn planting and milk products [6-11]; 
The MicroEnsure company designed an insurance project based on precipitation for farmers in Rwanda; the IFAD and WFP have designed agro-meteorological index insurance for rice planting and applied it in the Anhui province in China. Besides these experiences, Mexico, Brazil and Argentina have performed important experiments on the agricultural application of agro-meteorological index insurance [12-14].

In addition, Chinese scientists are currently researching the applications of agrometeorological index insurance in several provinces. Mao (2007) designed a meteorological insurance contract for orange orchards in the Zhejiang Province [15]; Lou (2009) designed an agro-meteorological index for freezing damage in orange [16]; Lu (2010) designed an agrometeorological index insurance contact for crops in northeast China [17]; and $\mathrm{Wu}$ (2010) designed an agro-meteorological index insurance product for rice cultivation in the Zhejiang Province [18]. Winter wheat is one of the most important crops of China; with a proportion of winter wheat to whole yield of more than $18 \%$, the safety of winter wheat cultivation is critical to the stability of China. Jiangsu is one of the most important provinces for winter wheat cultivation [19]. Our study offers a new solution for insuring winter wheat planting in the Jiangsu Province and provides experience for the study of agro-meteorological index insurance.

\section{Data and methods}

\subsection{Data}

The design of agro-meteorological index insurance requires meteorological and yield data. We obtained winter wheat yield data for the previous 13 years and meteorological data for the most recent 35 years from CMA for each city. Atmospheric circulation index data was obtained from the National Climate Center.

\subsection{Methods and models}

2.2.1 The winter wheat yield reduction rate: Jiang (2006) [20] considered that crop yield comprised trend and meteorological yields. A moving average is a useful method for separating meteorological yield. We chose five years of moving averages to separate winter wheat yield into trend yield and meteorological yield. The formula is:

$$
\mathrm{Y}=\mathrm{Y}_{\mathrm{t}}+\mathrm{Y}_{\mathrm{w}}
$$

where $Y$ is the whole yield, $Y_{t}$ is the trend yield, and $Y_{w}$ is the meteorological yield. Meteorological yield is primarily determined by meteorological conditions during winter wheat growth; a $Y_{w}>0$ means that the meteorological conditions are good for winter wheat growing, leading to a bumper harvest. The trend yield $Y_{t}$ is the result for settled soil.

The relative meteorological yield is:

$$
\mathrm{S}_{\mathrm{i}}=\frac{\mathrm{Y}-\mathrm{Y}_{\mathrm{t}}}{\mathrm{Y}_{\mathrm{t}}} \times 100 \%
$$

If $S_{i}<0$, the absolute value of $S_{i}$ is the winter wheat yield reduction proportion; if $S_{i} \geq 0$, the winter wheat yield reduction proportion is zero.

2.2.2 Winter wheat yield loss model design: Conventional agricultural insurance must calculate real loss. This procedure consumes considerable time and yields incorrect results, creating several problems in the application of insurance. One of the advantages of agro- 
meteorological index insurance is the absence of the need to determine real loss of crops. The model can be used to calculate meteorological loss, leading to a decision [21].

The yield of winter wheat is primarily influenced by temperature, precipitation, and other meteorological parameters, with the atmospheric circulation index also exerting some influence. We accordingly chose the main meteorological parameters of each ten-day period during the winter wheat growing season (from October to June) and some important atmospheric circulation indices for each month as selection factors. We first fitted a regression of the relative meteorological yield on each factor. If the regression passed the significance test, the factor was meaningful. We subsequently fitted a stepwise regression of the relative meteorological yield on all the meaningful factors using SPSS and built a winter wheat yield loss model for the Jiangsu Province. The model is:

$$
\mathrm{S}_{\mathrm{i}}=\mathrm{F}_{\mathrm{i}}(\mathrm{T}, \quad \mathrm{R}, \quad \mathrm{L}, \quad \mathrm{W}, \quad \mathrm{SN}, \mathrm{H})=\mathrm{a}+\sum_{\mathrm{j}=1}^{\mathrm{n}} \mathrm{b}_{\mathrm{ij}} \mathrm{y}_{\mathrm{ij}}
$$

In this model, $S_{i}$ is the relative meteorological yield, $T$ is temperature, $R$ is precipitation, $\mathrm{L}$ is sunshine time, $\mathrm{W}$ is wind, $\mathrm{SN}$ is snow, and $\mathrm{H}$ is the atmospheric circulation index. The variable $\mathrm{i}$ indexes the area serial number, $\mathrm{j}$ is the factor number, $\mathrm{a}$ and $\mathrm{b}$ are coefficients, and $\mathrm{y}$ is the chosen factor.

\subsection{Design of an agro-meteorological insurance index}

After a winter wheat yield loss model has been constructed, we can calculate the relative future meteorological yield and compensate. In this study, to obtain more yield data and more easily calculate a pure premium rate, we used the model to calculate the relative meteorological yield from 1978 to 1999 in Jiangsu province and applied it to yield data for the most recent 35 years.

In a given area, based on the relationship between yield and meteorological conditions, we decided that if the relative meteorological yield is lower than the given deductible amount, the insurance company must pay according to the agro-meteorological insurance index. Based on the data for the Jiangsu Province, we set the full insurance rate at 2000 per $\mathrm{mu}\left(666.7 \mathrm{~m}^{2}\right)$ and a premium based on the premium rate for each area. The agro-meteorological insurance index is based on the crop reduction rate:

$$
W= \begin{cases}0 & x \leq x_{c} \\ x & x>x_{c}\end{cases}
$$

In the above formula, $\mathrm{W}$ is the insurance index of the given area, $\mathrm{x}$ is the winter wheat reduction rate, and $\mathrm{x}_{\mathrm{c}}$ is the relative deductible amount.

Besides the calculation of the insurance index, another important task is to define the premium rate, which is calculated as follows: premium rate $=$ pure premium rate $\times(1+$ safety factor $) \times(1+$ business cost factor $) \times(1+$ profit rate $)$.

In this formula, the safety factor, business cost factor, and profit rate are determined by the situation of the insurance company; therefore, the most important task is to determine the pure premium rate.

There are at present two methods for calculating the pure premium rate [22-24]: the experience rate and output distribution model methods. The experience rate method is based on the theory of balance of receipts and payments; the premium over several years should be equal to the compensation over these years. The output distribution method is based on 
probability theory and statistics; to find the probability density function for crops, we must determine the pure premium rate.

The output distribution method requires knowing the probability density function for winter wheat; if the wrong function is chosen, the result will have a large error. In this study, we chose the experience rate method to determine the pure premium rate. If the deductible amount is $\mathrm{x}_{\mathrm{c}}$ and the calculated yield reduction rate is $\mathrm{x}$, the compensation rate for the year is:

$$
L_{i}= \begin{cases}0 & x \leq x_{c} \\ x & x>x_{c}\end{cases}
$$

The average compensation rate for $\mathrm{n}$ years is:

$$
\mathrm{L}=\frac{1}{\mathrm{n}} \sum_{\mathrm{t}=1}^{\mathrm{n}} \mathrm{L}_{\mathrm{i}}
$$

Based on the theory of balance of receipts and payments, we can set $\mathrm{L}$ as the approximate value of the pure premium rate.

\section{Insurance Product Design}

Because different areas have different meteorological disaster risks, deductible amounts in different areas are not identical. Using the experience rate method to calculate pure premium rates at the deductible amounts of $2.5 \%, 5 \%, 7.5 \%, 10 \%$, and $12.5 \%$ yields the pure premium rates for the whole province for each deductible amount. Using kriging interpolation method, we can compute the difference for each city. Based on pure premium rate calculation principles, higher the deductible amount, lower the pure premium rate. In real applications, the pure premium rate must not be extremely high because farmers will not buy the insurance nor will an excessively high deductible amount attract customers. We must determine the right deductible amount for each area and subsequently calculate the corresponding pure premium rate [25].

If premium rate $=$ pure premium rate $\times(1+$ safety factor $) \times(1+$ business cost factor $)$ $\times(1+$ profit rate $)$, and under normal conditions, we set the safety factor at $20 \%$, business cost factor at $20 \%$, and profit rate at $5 \%$, the premium rate $=$ pure premium rate $\times 1.512$. If according to the agricultural risks in the Jiangsu Province and experience, we set the premium rate at $10 \%$, the corresponding pure premium rate is $6.61 \%$. In this study, given a deductible amount, if the corresponding pure premium rate is less than 6.61 but close to $6.61 \%$, we select this deductible amount and pure premium rate for the area.

\subsection{Analysis of the pure premium rate of the Jiangsu Province for each deductible amount}

At the five deductible amounts, the pure premium rates in the Jiangsu Province are shown in the following figures. 


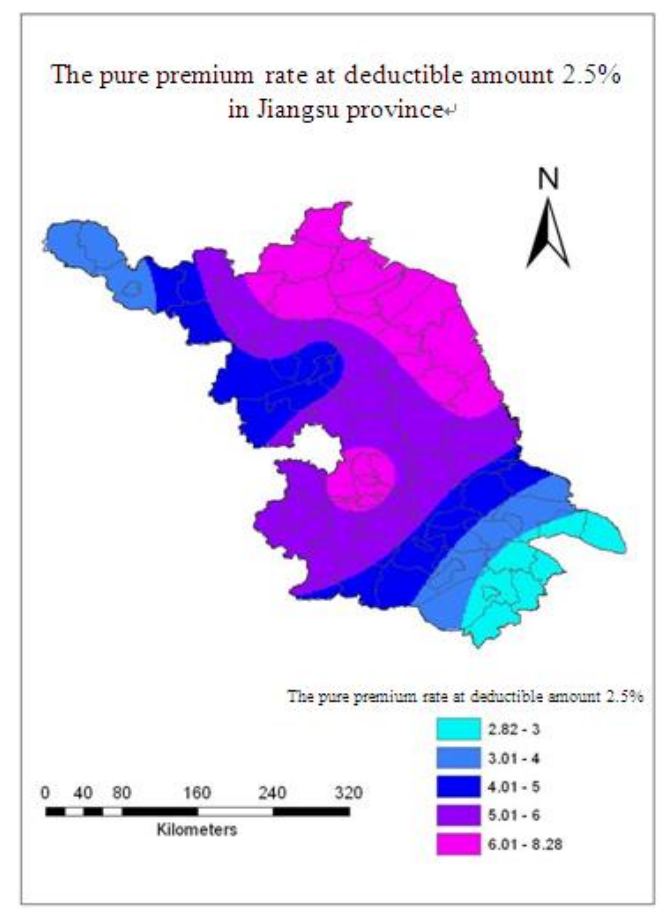

Figure 1. Pure premium rates at $2.5 \%$ deductible amount in the Jiangsu Province

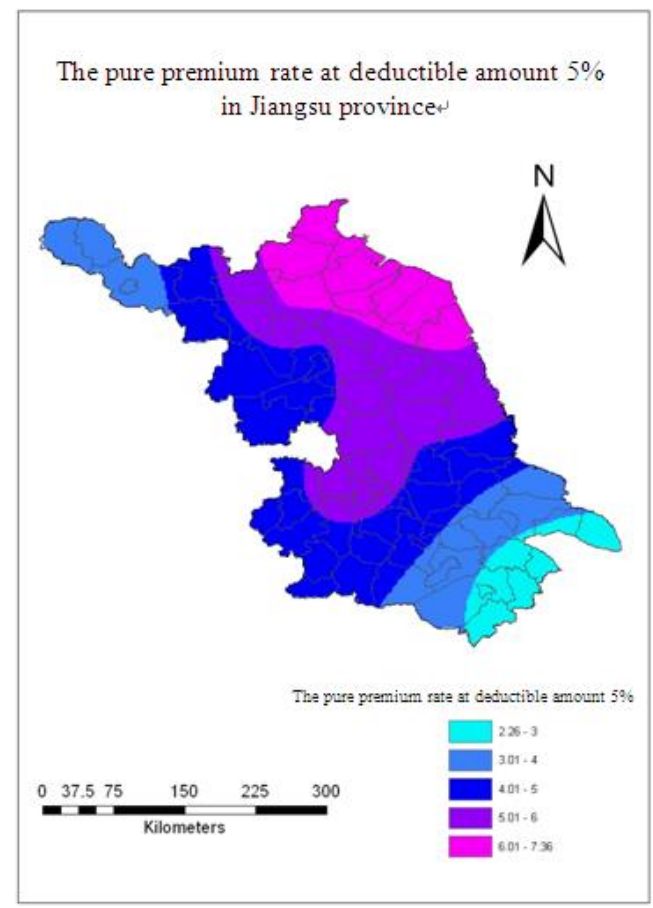

Figure 2. Pure premium rates at $5.0 \%$ deductible amount in the Jiangsu Province 


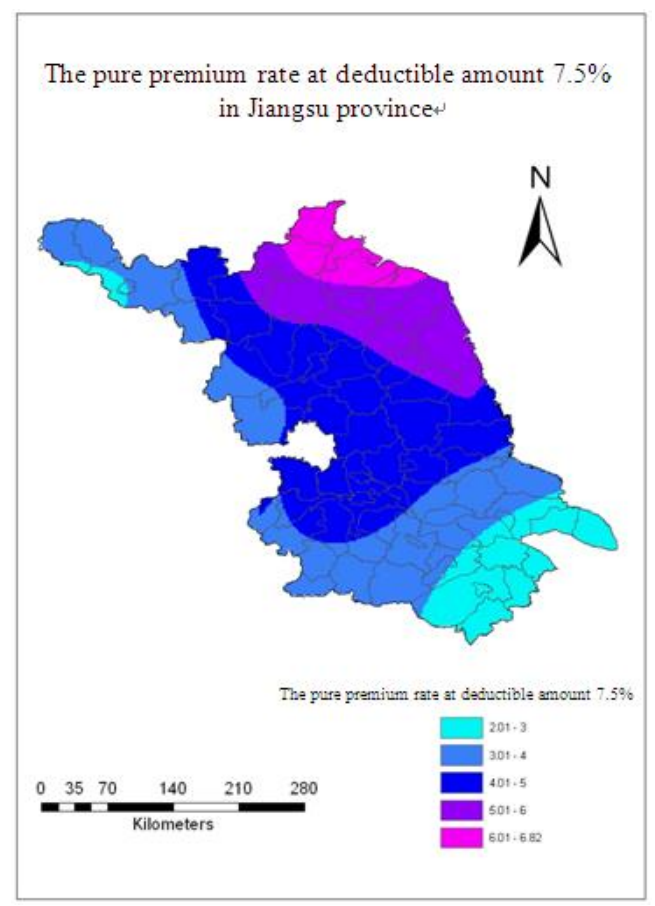

Figure 3. Pure premium rates at $7.5 \%$ deductible amount in the Jiangsu Province

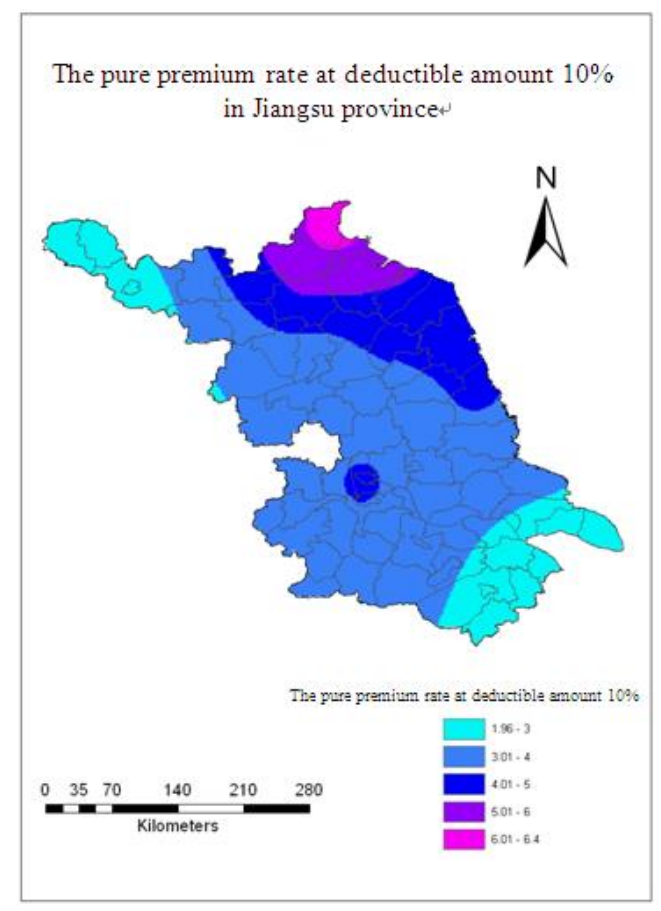

Figure 4. Pure premium rates at $\mathbf{1 0 . 0} \%$ deductible amount in the Jiangsu Province 


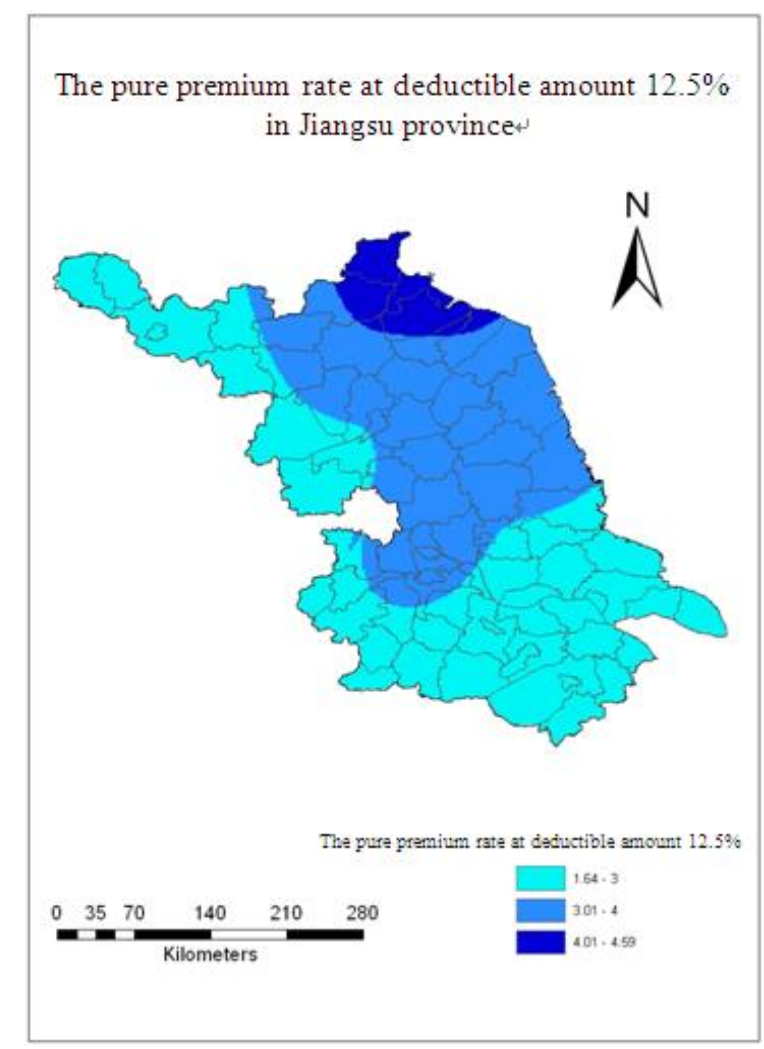

Figure 5. Pure premium rates at $12.5 \%$ deductible amount in the Jiangsu Province

From the figures, it is evident that the winter wheat pure premium rates in the Jiangsu Province are between $2.82 \%$ and $8.28 \%$ at a deductible amount of $2.5 \%$. The pure premium rates in the northeast of the Jiangsu Province are high, all exceeding 6\%. In this region including Lianyungang, Donghai, Xiangshui, Binhai, Sheyang, Dafeng, Muyang, and Yancheng, the meteorological disaster risk is large. The pure premium rate of Yangzhou is also greater than $6 \%$. The pure premium rates of the southeast and northwest of the Jiangsu Province are low, most being below 4\%. The pure premium rates of Suzhou, Changshu, and Kunshan are less than $3 \%$. The pure premium rates of the middle region are between $4 \%$ and $6 \%$.

The pure premium rates at $5 \%$ deductible amount are lower than those at $2.5 \%$ deductible amount. Winter wheat pure premium rates in Jiangsu province are between $2.26 \%$ and $7.36 \%$ at a $5 \%$ deductible amount. The pure premium rates in the northeast of Jiangsu province are high, all exceeding 6\%, and in this region, which includes Lianyungang, Donghai, Xiangshui, Binhai, and Sheyang, the meteorological disaster risk is also high. The pure premium rates in the southeast and northwest the Jiangsu Province are also low, most being below 4\%. The pure premium rates of Suzhou, Changshu, and Kunshan are also less than 3\%. The pure premium rates of several areas are below $5 \%$.

The pure premium rates at a $7.5 \%$ deductible amount are between $2.01 \%$ and $6.82 \%$. The pure premium rates in the northeast of the Jiangsu Province are high, all being above $6 \%$, but 
the area of this region is small, including only Ganyu, Lianyungang, and Guanyun. The pure premium rates in most places in Jiangsu province are less than $6 \%$ and several are below $5 \%$. The pure premium rates of southeast and northwest of the Jiangsu Province are also low, most being below $4 \%$ over this large region. The pure premium rates of Suzhou, Changshu, and Kunshan are below $3 \%$. The pure premium rates of the middle region are between $4 \%$ and $5 \%$.

The pure premium rates of southeast and northwest of the Jiangsu Province are low, most being below 3\%. This region includes Suzhou, Changshu, Kunshan, Xuzhou, Fengxian, and Peixian. The pure premium rates at $10 \%$ deductible amount continued to decrease, and are between $1.96 \%$ and $6.4 \%$. Only the pure premium rate of Ganyu is above 6\%. The pure premium rates of several northeast areas are above $5 \%$. The pure premium rates of most areas are below $4 \%$. The pure premium rates of the Jiangsu Province at a $12.5 \%$ deductible amount are extremely low, being between $1.64 \%$ and $4.59 \%$. The pure premium rates in the northeast of the Jiangsu Province are highest but are all below 5\%. The pure premium rates of the south and west of the Jiangsu Province are low, most being below 3\%. The pure premium rates of the remaining locations are between $3 \%$ and $4 \%$.

\subsection{Deductible amount design for different regions in the Jiangsu Province}

From the analysis of pure premium rates in the Jiangsu Province at different deductible amounts, we can understand that different regions should have different deductible amounts. Based on the theory of deductible amount determination, by which the corresponding pure premium rate should be less than $6.61 \%$ and close to $6.61 \%$, we divided the Jiangsu Province into three regions by deductible amount. The regions, pure premium rates, and pure premiums are shown in Tables 1-3.

Table 1. Pure premium rates and pure premium for each county (deductible amount $=7.5 \%$ )

\begin{tabular}{ccc||ccc}
\hline City & $\begin{array}{c}\text { Pure premium } \\
\text { rate [\%] }\end{array}$ & $\begin{array}{c}\text { Pure } \\
\text { premium } \\
{[\text { RMB } ¥]}\end{array}$ & City & $\begin{array}{c}\text { Pure premium } \\
\text { rate [\%] }\end{array}$ & $\begin{array}{c}\text { Pure premium } \\
{[\text { RMB } ¥]}\end{array}$ \\
\hline Lianyungang & 6.32 & 126.4 & Jianhu & 5.12 & 102.4 \\
Donghai & 6.03 & 120.6 & Xiangshui & 5.97 & 119.4 \\
Guanyun & 6.56 & 131.2 & Funing & 4.65 & 93.0 \\
Ganyu & 6.64 & 132.8 & Sheyang & 4.81 & 96.2 \\
Guannan & 5.79 & 115.8 & Binhai & 5.56 & 111.2 \\
Muyang & 5.38 & 107.6 & Dafeng & 4.46 & 89.2 \\
Yancheng & 4.32 & 86.4 & Lianshui & 4.72 & 94.4 \\
\hline
\end{tabular}


Table 2. Pure premium rates and pure premium for each county (deductible amount $=5.0 \%$ )

\begin{tabular}{ccc||ccc}
\hline City & $\begin{array}{c}\text { Pure premium } \\
\text { rate }[\%]\end{array}$ & $\begin{array}{c}\text { Pure premium } \\
{[\text { RMB } ¥]}\end{array}$ & City & $\begin{array}{c}\text { Pure premium } \\
\text { rate [\%] }\end{array}$ & $\begin{array}{c}\text { Pure premium } \\
{[\text { RMB } ¥]}\end{array}$ \\
\hline Xinyi & 5.32 & 106.4 & Yangzhou & 5.18 & 103.6 \\
Dongtai & 4.51 & 90.2 & Baoying & 5.39 & 107.8 \\
Huai-an & 5.14 & 102.8 & Gaoyou & 5.22 & 104.4 \\
Hongze & 4.19 & 83.8 & Yizheng & 5.43 & 108.6 \\
Jinhu & 4.98 & 99.6 & Zhenjiang & 4.88 & 97.6 \\
Suqian & 4.37 & 87.4 & Danyang & 4.76 & 95.2 \\
Siyang & 4.65 & 93.0 & Yangzhong & 4.99 & 99.8 \\
Hai-an & 4.09 & 81.8 & Jurong & 4.36 & 87.2 \\
Rudong & 3.97 & 79.4 & Taizhou & 4.77 & 95.4 \\
Rugao & 4.13 & 82.6 & Tauxing & 4.53 & 90.6 \\
Nanjing & 4.76 & 95.2 & Jiangyan & 5.20 & 104.0 \\
Lishui & 4.50 & 90.0 & Jingjiang & 5.36 & 107.2 \\
Gaochun & 4.62 & 92.4 & Xinghua & 5.54 & 110.8 \\
\hline
\end{tabular}

Table 3. Pure premium rates and pure premium for each county (deductible amount $\mathbf{=} 2.5 \%$ )

\begin{tabular}{ccc||ccc}
\hline City & $\begin{array}{c}\text { Pure } \\
\text { premium rate } \\
{[\%]}\end{array}$ & $\begin{array}{c}\text { Pure premium } \\
{[\text { RMB } ¥]}\end{array}$ & City & $\begin{array}{c}\text { Pure } \\
\text { premium rate } \\
{[\%]}\end{array}$ & $\begin{array}{c}\text { Pure premium } \\
{[\text { RMB } ¥]}\end{array}$ \\
\hline Xuzhou & 3.25 & 65.0 & Jintan & 4.23 & 84.6 \\
PeiXian & 3.56 & 71.2 & Liyang & 4.15 & 83.0 \\
FengXian & 3.02 & 60.4 & Suzhou & 2.78 & 55.6 \\
Suining & 4.12 & 82.4 & Changshu & 3.01 & 60.2 \\
Pizhou & 4.32 & 86.4 & Zhangjiagang & 2.79 & 55.8 \\
Xuyi & 4.21 & 84.2 & Taicang & 2.31 & 46.2 \\
Sihong & 4.03 & 80.6 & Kunshan & 2.12 & 42.4 \\
Wuxi & 3.19 & 63.8 & Wujiang & 2.15 & 43.0 \\
Jiangyin & 3.45 & 69.0 & Nantong & 3.17 & 63.4 \\
Yixing & 3.41 & 68.2 & Haimen & 2.77 & 55.4 \\
Changzhou & 3.20 & 64.0 & Qidong & 2.45 & 49.0 \\
\hline
\end{tabular}

The first region, located in the northeast of the Jiangsu Province, is given a large deductible amount of $7.5 \%$ because it has a large meteorological disaster risk, and the cities in this region have large pure premium rates. In the second region located in the middle and west of the Jiangsu Province, the deductible amount is 5\%, the meteorological disaster risk is lower than that in the first region, and the pure premium rates are also lower. The third region includes the northwest and south of Jiangsu province, where the deductible amount of this region is $2.5 \%$ and the pure premium rates are lowest.

\section{Conclusions and Discussion}

This study has shown that agro-meteorological insurance is useful for winter wheat protection in the Jiangsu Province. By building a yield loss model, we improve the 
practicability of the insurance; insurance companies need not visit every farmer to calculate the real loss, but can make decisions based only on meteorological data. By solving the problems of conventional insurance products, agro-meteorological index insurance represents an important innovation in the study of agricultural insurance.

Compared with other studies, ours has some advantages. First, we have incorporated directly correlated meteorological parameters and indirectly correlated atmospheric circulation index into the yield loss model. The model is, therefore, highly credible. Second, using the kriging method in Arcgis and pure premium rates of the Jiangsu Province at different deductible amounts, we have divided the Jiangsu Province into three regions using different deductible amounts. This article contributes to the study of agro-meteorological index insurance.

Some deficiencies remain in the study. Sufficient data are lacking for the selected sites and the length of the data sequence is extremely short. These deficiencies are likely to influence the results. Moreover, in choosing a pure insurance rate calculation method, we may need to contrast several methods to give better results. In future studies, we hope to obtain more detailed data and compare a variety of methods for designing winter wheat meteorological insurance index products in the Jiangsu Province.

\section{Acknowledgements}

This research was supported through Public Service Sectors (Meteorology) Industryspecific research facilities funding (2010). It is one part of the project: "The research in the risk zoning of the typical regional meteorological disasters (GYHY201106019)." The authors would also like to thank the Provincial Bureau of Jiangsu for help in conducting the empirical research by providing statistical data.

\section{References}

[1] J. B. Barry and M. Olivier, Am. J. Agric. Econ., vol. 89, (2007), pp. 1241.

[2] P. Varangis, J. Skees and B. Barnett, in Climate Risk and the Weather Market: Financial Risk Management with Weather Hedges, Edited Dischel R S, Risk Books, London (2005), pp. 279-294.

[3] U. Hess and J. Syroka, "Weather-based insurance in Southern Africa: The case of Malawi//Agriculture and Rural Development Discussion Paper 13”, The World Bank, Washington, DC, (2005), pp. 1-78.

[4] United States Agency for International Development, "Index Insurance for Weather Risk in Lower Income Countries", Lexington: GlobalAgRisk, (2006).

[5] J. Skees, P. Hazell and M. Miranda, "New Approaches to Public/Private Crop Yield Insurance", (1999).

[6] M. J. Miranda, Am. J. Agric. Econ., vol. 73, (1991), pp. 233.

[7] B. K. Goodwin and A. P. Ker, Am. J. Agric. Econ., vol. 80, (1998), pp. 139.

[8] O. Mahul, Am. J. Agric. Econ., vol. 81, (1999), pp. 75.

[9] A. P. Ker and B. K. Goodwin, Am. J. Agric. Econ., vol. 3, (2008), pp. 463.

[10] S. W. Martin, B. J. Barnett and K. H. Coble, Journal of Agricultural and Resource Economics, vol. 21, (2001), pp. 261.

[11] O. Mahul and D. Vermersch, European Review of Agricultural Economics, vol. 21, (2000), pp. 109.

[12] C. G. Turvey, Review of Agricultural Economics, vol. 23, (2001), pp. 333.

[13] M. Cao and J. Wei, The Journal of Futures Markets, vol. 24, (2004), pp. 1065.

[14] J. Skees, S. Gober, P. Varangis, R. Lester and V. Kalavakonda, Developing Rainfall-Based Index Insurance in Morocco // Policy Research Working Paper No.2577. World Bank, Washington, DC, USA (2001), pp. 1-37.

[15] M. Yu-ding, W. Li-hong, M. Chang-ming, Y. Yi-ping and S. Gao-li, Chinese Journal of Agrometeorology, vol. 28, (2007), pp. 26.

[16] L. Wei-ping, W. Li-hong, N. Hu-ping, T. Qi-yi and M. Yu-ding, Scientia Agricultura Sinica, vol. 42, (2009), pp. 1339.

[17] L. Ping, "Design of Weather Index Crop Insurance Contract for Northeast China", Tsinghua University, (2010). 
[18] W. Li-hong, L. Wei-ping, Y. Yi-ping, M. Yu-ding and S. Gao-li, Scientia Agricultura Sinica, vol. 43, (2010), pp. 4942.

[19] W. Bingjuan and Z. Xuhui, Modern Agricultural Science and Technology, vol. 282, (2009).

[20] J. Huifei, W. De-yong, L. Shu-hua, L. Shu-yan and W. Wen-liang, Journal of China Agricultural University, vol. 11, (2006), pp. 47.

[21] L. Wei-ping, W. Li-hong, Q. Xin-fa, T. Qi-yi, S. Gao-li and M. Yu-ding, Journal of Natural Resources, vol. 24, (2009), pp. 1330.

[22] J. Hui-fei, Journal of China Agricultural University, vol. 14, (2009), pp. 109.

[23] W. Ke, "A Study on the Influence of Flexible Crop Yield Distributions on Crop Insurance Premium Rate", The Chinese Academy of Agricultural Sciences, (2008).

[24] Z. Qiao and W. Ke, Agricultural Outlook, vol. 7, (2007).

[25] W. Si-bo and M. Qiong, Journal of Shijiazhuang Tiedao University (Social Science), vol. 13, (2012).

\section{Authors}

\section{Cao Jie}

A Professor with a Ph.D. in Management, 40 years old. His main research direction is emergency management, climate change, and public meteorology.

\section{Li Sijia}

A master's student from Taizhou county in the Jiangsu Province, 24 years old. Her main research direction is climate change and public meteorology.

\section{Yang Li}

A master's student, 26 years old. Her main research direction is climate change and public meteorology. 
International Journal of Hybrid Information Technology Vol.6, No.5 (2013) 